\title{
Two-year safety and clinical outcomes in chronic ischemic stroke patients after implantation of modified bone marrow-derived mesenchymal stem cells (SB623): a phase 1/2a study
}

\author{
Gary K. Steinberg, MD, PhD,, 2 Douglas Kondziolka, MD, ${ }^{3}$ Lawrence R. Wechsler, MD, ${ }^{4}$ \\ L. Dade Lunsford, MD, ${ }^{5}$ Anthony S. Kim, MD, MAS, ${ }^{6}$ Jeremiah N. Johnson, MD, ${ }^{1}$ \\ Damien Bates, MD, PhD, ${ }^{7}$ Gene Poggio, PhD, ${ }^{8}$ Casey Case, PhD, ${ }^{7}$ Michael McGrogan, PhD, ${ }^{7}$ \\ Ernest W. Yankee, PhD, ${ }^{7}$ and Neil E. Schwartz, MD, PhD²

\begin{abstract}
1Department of Neurosurgery and Stanford Stroke Center and '2Department of Neurology and Neurological Sciences and Stanford Stroke Center, Stanford University School of Medicine and Stanford Health Care, Stanford, California; ${ }^{3}$ Department of Neurosurgery, New York University and NYU Langone Medical Center, New York, New York; Departments of ${ }^{4}$ Neurology and ${ }^{5}$ Neurosurgery, University of Pittsburgh Medical School and University of Pittsburgh Medical Center, Pittsburgh, Pennsylvania; ${ }^{6}$ Department of Neurology, University of California, San Francisco, California; ${ }^{7}$ SanBio, Inc., Mountain View, California; and ${ }^{8}$ Biostatistical Consulting Inc., Lexington, Massachusetts
\end{abstract}

OBJECTIVE The aim of this study was to evaluate the safety and clinical outcomes associated with stereotactic surgical implantation of modified bone marrow-derived mesenchymal stem cells (SB623) in patients with stable chronic ischemic stroke.

METHODS This was a 2-year, open-label, single-arm, phase 1/2a study; the selected patients had chronic motor deficits between 6 and 60 months after nonhemorrhagic stroke. SB623 cells were administered to the target sites surrounding the subcortical stroke region using MRI stereotactic image guidance.

RESULTS A total of 18 patients were treated with SB623 cells. All experienced at least 1 treatment-emergent adverse event (TEAE). No patients withdrew due to adverse events, and there were no dose-limiting toxicities or deaths. The most frequent TEAE was headache related to the surgical procedure $(88.9 \%)$. Seven patients experienced 9 serious adverse events, which resolved without sequelae. In 16 patients who completed 24 months of treatment, statistically significant improvements from baseline (mean) at 24 months were reported for the European Stroke Scale (ESS) score, 5.7 (95\% Cl 1.4-10.1, p < 0.05); National Institutes of Health Stroke Scale (NIHSS) score, $-2.1(95 \% \mathrm{Cl}-3.3$ to $-1.0, p<$ 0.01), Fugl-Meyer (F-M) total score, 19.4 (95\% Cl 9.9-29.0, p < 0.01); and F-M motor scale score, 10.4 (95\% Cl 4.0-16.7, $p<0.01)$. Measures of efficacy reached plateau by 12 months with no decline thereafter. There were no statistically significant changes in the modified Rankin Scale score. The size of transient lesions detected by T2-weighted FLAIR imaging in the ipsilateral cortex at weeks $1-2$ postimplantation significantly correlated with improvement in ESS (0.619, $p$ $<0.05)$ and NIHSS $(-0.735, p<0.01)$ scores at 24 months.

CONCLUSIONS In this completed 2-year phase 1/2a study, implantation of SB623 cells in patients with stable chronic stroke was safe and was accompanied by improvements in clinical outcomes.

Clinical trial registration no.: NCT01287936 (clinicaltrials.gov)

https://thejns.org/doi/abs/10.3171/2018.5.JNS173147

KEYWORDS bone marrow-derived mesenchymal stem cells; SB623 cells; stable chronic stroke; stereotactic transplantation; phase 1/2a study; vascular disorders

ABBREVIATIONS ESS = European Stroke Scale; F-M = Fugl-Meyer; FMMS = Fugl-Meyer motor scale; HLA = human leukocyte antigen; mRS = modified Rankin Scale; NIHSS = National Institutes of Health Stroke Scale; PISCES = Pilot Investigation of Stem Cells in Stroke; SAE = serious adverse event; TEAE = treatment-emergent adverse event. SUBMITTED December 19, 2017. ACCEPTED May 10, 2018.

INCLUDE WHEN CITING Published online November 23, 2018; DOI: 10.3171/2018.5.JNS173147. 
$\mathrm{S}$ TROKE is a major cause of death in the United States and, for surviving patients, a cause of enduring disability. ${ }^{4}$ The prevalence of stroke in the United States during 2014 was estimated to be 7.2 million cases, with 795,000 new or recurrent stroke cases being reported. ${ }^{4} \mathrm{Al}-$ though $80 \%$ of stroke patients survive for 1 year following the event, more than $70 \%$ have long-term disabilities. ${ }^{25}$

Stroke is divided into acute, subacute, and chronic phases, with the acute phase occurring within 24 hours of the ischemic event. ${ }^{7}$ The only treatments currently approved for acute stroke are intravenous tissue plasminogen activator and intraarterial mechanical thrombectomy, which are used in less than $10 \%$ and $1 \%$ of patients, respectively. 2,27,29 The subacute phase of stroke starts at 24 hours and lasts up to 3 months, during which time patients develop neurological and functional disabilities..$^{9,24,42}$ The chronic phase of stroke starts at 3 months and often sees the response to rehabilitation plateau, leaving many patients with significant chronic neurological and functional disabilities. ${ }^{31,36}$ Despite this burden, there are no approved treatments for the chronic phase of stroke.

Phase 1 and 2 clinical studies investigating the neurorestorative effects of several cell types implanted by various routes of administration in patients in the acute to chronic phases of stroke are ongoing. . $^{2,820,21,23,28,33,37}$ Phase 1 studies assess safety and dosage, enroll healthy volunteers or stroke patients, and are of several months' duration. Phase 2a proof-of-concept studies are designed to assess efficacy, enroll stroke patients, and last up to 2 years duration. Although phase 2a studies assess efficacy, controls are provided by baseline values, as there is no expectation of a separate control arm within the study.

We recently reported 1-year interim data from our phase $1 / 2$ a study, in which chronic stroke patients who were enrolled at least 6 months after stroke onset underwent intracerebral stereotactic implantation of modified bone marrow-derived mesenchymal stem cells (SB623 cells). ${ }^{33}$ The treatment was generally safe, well tolerated, and associated with significant improvements in clinical outcomes. In addition, the majority of patients in the study experienced transient lesions detected by T2-weighted FLAIR imaging in the ipsilateral cortex at weeks 1-2 postimplantation of SB623 cells. The lesions on T2-weighted FLAIR imaging resolved by months 1-2 postimplantation, and their size significantly correlated with improvement in clinical outcomes scales at 1 year. ${ }^{33}$ Data from Pilot Investigation of Stem Cells in Stroke (PISCES), a phase 1 clinical study of patients with chronic stroke who underwent stereotactic implantation of modified human neural stem cells into the putamen, reported favorable safety with improvement of clinical outcomes at 2 years. ${ }^{21}$ Lesions seen in the ipsilateral cortex on T2-weighted FLAIR imaging in a minority of patients in the study were observed at 1 month and persisted for 2 years, with no correlations to clinical outcomes. In addition, a phase 2 study of patients with chronic stroke reported that intracerebral stereotactic implantation of peripheral blood stem cells was safe and was associated with improvement of clinical outcomes at 1 year. $^{8}$

SB623 cells are produced by the transient transfection of allogeneic modified bone marrow-derived mesenchy- mal stem cells with a plasmid vector encoding the human Notch-1 intracellular domain. ${ }^{1}$ Preclinical studies of chronic ischemic stroke in which human and rodent SB623 cells were stereotactically implanted into the striatum of a rat resulted in reduced peri-infarct cell loss coupled with improvements of neurological and locomotor function. ${ }^{44}$

Here, we report our completed, open-label, single-arm, phase 1/2a study (NCT01287936), in which, consistent with the 1-year interim data, treatment of chronic stroke patients with SB623 cells at 2 years continued to be safe and was associated with sustained significant improvements in clinical outcomes.

\section{Methods}

The design of this phase $1 / 2$ a study, together with methods used in data analyses, have been described previously by Steinberg and colleagues. ${ }^{33}$

\section{Patients}

A total of 379 patients were screened, and 18 patients who were at least 6 months post-stroke onset and had chronic motor deficits secondary to nonhemorrhagic stroke were enrolled in the study (Table 1). The clinical trial registration number for this study is NCT01287936 (clinicaltrials.gov).

The status of stable chronic stroke was confirmed by 2 evaluations with the National Institutes of Health Stroke Scale (NIHSS), which were conducted within 3 weeks of enrollment with no score change of greater than \pm 1 point. ${ }^{22,23}$ All implantation surgeries were conducted at the Stanford University School of Medicine/Stanford Health Care and University of Pittsburgh Medical Center (UPMC) between September 2011 and August 2013. Institutional review boards reviewed and approved study protocols at each site, and patients provided written informed consent. Study inclusion and exclusion criteria are listed in Table 2.

The study population was composed of 18 patients who were enrolled, received cell treatment, and had any postbaseline data. Clinical evaluations were conducted in the intent-to-treat population $(\mathrm{n}=18)$, which included 16 patients who had 24-month follow-up data (2 patients withdrew and were lost to follow-up). Acute and long-term clinical outcomes were evaluated using the European Stroke Scale (ESS; the primary outcome endpoint at 6 months), ${ }^{18}$ NIHSS, ${ }^{6,17}$ modified Rankin Scale (mRS), ${ }^{5,30}$ and Fugl-Meyer (F-M) score. ${ }^{15,16,32}$

\section{Study Visit Schedule}

The study visit schedule was as follows: screen 1 (study week -3 ); screen 2 (study week -1 ); baseline (study day: -2 to -1 ); enrollment (study day -1 to 1 ); surgical procedure (day 1); visits (days 2 and 8 and months 1, 2, 3, 4, 6, 9, 12, and 24). Assessments were conducted at each visit.

\section{SB623 Cells, Study Design, Dosing, and Administration}

SB623 cells were produced using Good Manufacturing Practices and are in clinical development as an allogeneic cell treatment for patients with chronic motor deficit 
secondary to stable ischemic stroke. During the study, 18 patients were assigned to 1 of 3 dose-escalation cohorts of 6 patients each; the 3 cohorts received single doses of 2.5 $\times 10^{6}, 5.0 \times 10^{6}$, or $10 \times 10^{6} \mathrm{SB} 623$ cells implanted using MRI stereotactic technique. The peri-infarct subcortical stroke region was targeted. Through a single burr hole, 3 tracks were planned so that trajectories were spaced by $5-6 \mathrm{~mm}$ at the target. The target locations were selected to be closest to the motor pathway based on the patient's own neuroanatomy. The Pittsburgh Implantation Cannula was stereotactically inserted down to the deepest target point for the first implantation. Five 20- $\mu$ l volumes of cells were injected at a rate of $10 \mu \mathrm{l} / \mathrm{min}$ into 5 implantation sites, slowly withdrawing the cannula so that the implantations were spaced as equally as possible (intervals of 4-5 $\mathrm{mm}$ ), resulting in 2 or 3 implants within the peri-infarct region distal to the stroke area and 2 or 3 implants within the peri-infract region proximal to the stroke area. This procedure was repeated with two other needle tracks with different trajectories, inserted through the same burr hole.

\section{Safety}

During the study, treatment-emergent adverse events (TEAEs) were defined as any event not present prior to initiation of the cell treatment/surgical procedure or any event already present that worsened in frequency or intensity after exposure to the cell treatment and surgical procedure. Adverse events were classified by investigators as mild, moderate, severe, or life-threatening and by their relationship to cell treatment and/or the surgical procedure (Table 3).

\section{Statistical Analysis}

Descriptive statistics were calculated for both continuous variables (number of patients, mean, median, minimum, maximum, standard deviation, standard error of the mean, and $95 \%$ confidence interval $[95 \% \mathrm{CI}]$ ), and categorical variables (number of patients and percentage of patients in each category). The Wilcoxon signed-rank test was used to evaluate the significance of change from baseline for prospectively defined clinical outcomes ( $\mathrm{p}<$ 0.05 considered as statistically significant). Pearson correlations were used to evaluate associations between volume of postimplantation transient lesions detected by T2weighted FLAIR imaging and clinical outcomes $(\mathrm{p}<0.05$ considered as statistically significant). Analyses were conducted using Statistical Analysis System software (version 9.2, SAS Institute).

\section{Results}

\section{Evaluation of Safety}

Twenty-four months after implantation of SB623 cells, all patients in the study population $(n=18)$ had experienced at least 1 TEAE (Table 4). No patient withdrew from the study due to adverse events, and there were no dose-limiting toxicities or deaths. Overall, the most frequently encountered TEAEs (measured as a percentage of patients) were surgical procedure-related headache (88.9\%), nausea (33.3\%), depression (22.2\%), muscle spasticity (22.2\%), vomiting (22.2\%), blood glucose increase
TABLE 1. Baseline demographics (intent to treat population)

\begin{tabular}{|c|c|}
\hline Characteristics & $n=18$ \\
\hline \multicolumn{2}{|l|}{ Age, y } \\
\hline Mean (SD) & $61.3(10.3)$ \\
\hline Median & 64.0 \\
\hline Range: min-max & $33-75$ \\
\hline \multicolumn{2}{|l|}{ Sex, n (\%) } \\
\hline Male & $7(38.9)$ \\
\hline Female & $11(61.1)$ \\
\hline \multicolumn{2}{|l|}{ Race, $\mathrm{n}(\%)$} \\
\hline White & $12(66.7)$ \\
\hline Black & $1(5.6)$ \\
\hline Asian & $5(27.8)$ \\
\hline $\begin{array}{l}\text { Native Hawaiian or other Pacific } \\
\text { Islander }\end{array}$ & $0(0.0)$ \\
\hline American Indian or Alaska native & $0(0.0)$ \\
\hline Other & $0(0.0)$ \\
\hline \multicolumn{2}{|l|}{ Ethnicity, n (\%) } \\
\hline Hispanic or Latino & $0(0.0)$ \\
\hline Not Hispanic or Latino & $18(100.0)$ \\
\hline Mean time (range) post stroke (months) & $22.0(7-36)$ \\
\hline Mean size (range) of infarct $\left(\mathrm{cm}^{3}\right)$ & $42.3(1.0-87.0)$ \\
\hline \multicolumn{2}{|l|}{$\begin{array}{l}\text { Mean clinical outcome endpoints at } \\
\text { baseline (SD; } 95 \% \mathrm{Cl})\end{array}$} \\
\hline \multicolumn{2}{|l|}{$\begin{array}{l}\text { Baseline measures of clinical outcome } \\
\text { end points (SD; } 95 \% \mathrm{Cl} \text { ) }\end{array}$} \\
\hline ESS & $58.44(6.27 ; 55.3-61.6)$ \\
\hline NIHSS & $9.3(1.7 ; 8.5-10.2)$ \\
\hline $\mathrm{mRS}$ & $3.22(0.43 ; 3.0-3.4)$ \\
\hline F-M total score & $133.61(20.90 ; 123.2-144.0)$ \\
\hline F-M motor function total score & $30.44(15.14 ; 22.9-38.0)$ \\
\hline
\end{tabular}

Max $=$ maximum; $\min =$ minimum .

Reproduced with permission from Steinberg GK, Kondziolka D, Wechsler LR, Lunsford LD, Coburn ML, Billigen JB, Kim AS, Johnson JN, Bates D, King B, Case C, McGrogan M, Yankee EW, Schwartz NE: Clinical outcomes of transplanted modified bone marrow-derived mesenchymal stem cells in stroke: a phase 1/2a study. Stroke 47:1817-1824, 2016. One value has been modified.

(16.7\%), C-reactive protein increase (16.7\%), constipation $(16.7 \%)$, fatigue $(16.7 \%)$, pain in extremity $(16.7 \%)$, and urinary tract infection (16.7\%) (Table 4). Of TEAEs that occurred with $\geq 10 \%$ frequency, the vast majority did so during the 1st year after implantation of SB623 cells (65 TEAEs in the 1st year vs 11 in the 2 nd year). During the 2nd year after implantation, 2 cases each of headache, dysphagia, hypesthesia, and muscle spasms and single cases of constipation, pain in extremity, and urinary tract infection were reported. During the study, the majority of TEAEs were assessed as being of mild (11.1\%) or moderate $(50.0 \%)$ intensity. In addition, no correlation between the frequency of TEAEs and SB623 cell dose levels was observed.

During the 24 months after implantation of SB623 cells, investigators assessed that $94.4 \%$ of patients (17 of 18) experienced a TEAE that was unrelated, $55.6 \%$ (10 of 
TABLE 2. Study inclusion and exclusion criteria

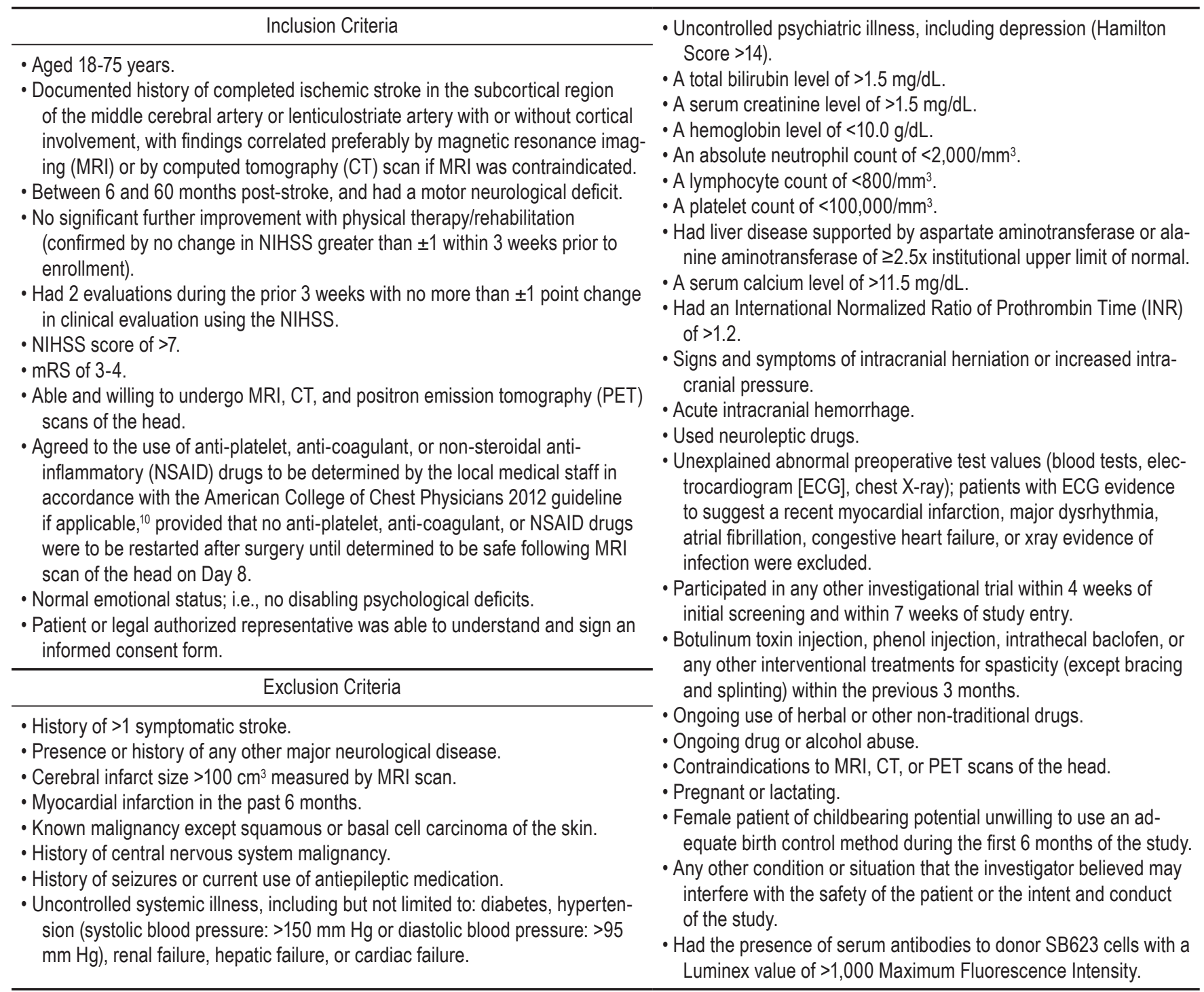

Reproduced with permission from Steinberg et al.: Stroke 47:1817-1824, 2016.

18) experienced a TEAE that was unlikely, and a single patient $(5.6 \%)$ experienced a TEAE that was possibly related to cell treatment (muscle spasticity) (Table 5). No TEAEs were assessed as probably or definitely related to cell treatment. Overall, a total of 28 TEAEs were assessed as being related or unrelated to cell treatment during the 1st year after implantation, with no additional TEAEs occurring during the 2nd year.

During the 24 months after implantation of SB623 cells, a greater number of patients experienced TEAEs that were possibly related to surgical procedure than were possibly related to cell treatment $(50.0 \%$ vs $5.6 \%)$. Furthermore, $55.6 \%$ of patients (10 of 18) experienced a TEAE that was probably, and $44.4 \%$ ( 8 of 18) experienced a TEAE that was definitely related to the surgical procedure (Table 5). The most frequently reported TEAE that was assessed as probably or definitely related to the surgical procedure was headache $(66.7 \%, 12$ of 18 patients) (Table 5). Over- all, a total of 46 TEAEs were assessed as being related or unrelated to surgical procedure during the 1st year after implantation, with an additional 4 new TEAEs occurring during the 2 nd year.

In the 24-month duration of this study, 7 patients experienced 9 serious adverse events (SAEs), with no apparent trend between cell dose and frequency of SAEs (Table 6). Four SAEs were assessed as unrelated to both cell treatment and surgical procedure. All SAEs were assessed as being unrelated or unlikely to be related to cell treatment. Single cases of pneumonia, seizure, and subdural hematoma were possibly, probably, and definitely, respectively, related to the surgical procedure. A total of 6 patients experienced 7 SAEs during the 1st year after implantation, with a single patient experiencing 2 SAEs during the 2 nd year. All patients who experienced SAEs were provided with supportive therapy and recovered or resolved from the event without sequelae. 
TABLE 3. Relationship of adverse events to cell treatment and surgical procedure

\begin{tabular}{ll}
\hline Description & \multicolumn{1}{c}{ Relationship } \\
\hline Unrelated & $\begin{array}{c}\text { No temporal relationship to cell treatment/surgical procedure, or the presence of a reasonable causal relationship between another } \\
\text { drug, concurrent disease, or circumstance and the AE. }\end{array}$ \\
\hline Unlikely & $\begin{array}{c}\text { A temporal relationship to cell treatment/surgical procedure, but no reasonable causal relationship between the cell treatment/surgical } \\
\text { procedure and the AE. }\end{array}$ \\
\hline Possibly & $\begin{array}{c}\text { A reasonable causal relationship between the cell treatment/surgical procedure and the AE. Information related to withdrawal of cell } \\
\text { treatment/surgical procedure was lacking or unclear. }\end{array}$ \\
\hline Probably & $\begin{array}{c}\text { A reasonable causal relationship between the cell treatment/surgical procedure and the AE. The event responded to withdrawal of cell } \\
\text { treatment/surgical procedure. Re-challenge was not required. }\end{array}$ \\
\hline Definitely & $\begin{array}{c}\text { A reasonable causal relationship between the cell treatment/surgical procedure and the AE. The event responded to withdrawal of cell } \\
\text { treatment/surgical procedure, and recurred with re-challenge, when clinically feasible. }\end{array}$ \\
\hline
\end{tabular}

$\mathrm{AE}=$ adverse event.

Reproduced with permission from Steinberg et al.: Stroke 47:1817-1824, 2016.

There were no clinically meaningful changes or trends in cytokines (tumor necrosis factor- $\alpha$, interleukin- 6 , and interferon- $\gamma$ ), vital signs, hematological parameters, or biochemical parameters after 24 months.

During the study, no patient developed antibodies to SB623 human leukocyte antigens (HLAs). One patient was found to have preexisting antibodies to SB623 HLAs, the median fluorescence intensity of which decreased after exposure to SB623. Antibodies to SB623 HLAs in this patient were found at each visit to month 9, but were not present at month 12 . No adverse events were associated with the presence of antibodies to SB623 HLAs in this patient.

\section{Evaluation of Clinical Outcomes}

The evaluation of clinical outcomes using ESS, NIHSS, mRS, F-M, and Fugl-Meyer motor scale (FMMS) scores was conducted on all patients. The mean (SD) ESS total score at baseline was 58.4 (6.3), which improved significantly at each time point beginning at month 1 . Compared with baseline, the mean ESS total score improved significantly by $6.5(95 \%$ CI $2.6-10.4, \mathrm{p}<0.01)$ at 6 months (primary outcome), $6.9(95 \%$ CI $3.5-10.3, \mathrm{p}<0.001)$ at 12 months, and 5.7 (95\% CI 1.4-10.1, p < 0.05) at 24 months (Fig. 1A).

The mean (SD) NIHSS total score at baseline was 9.3 (1.7), which improved significantly at each time point. Compared with baseline, the mean NIHSS total score improved significantly by -1.9 (95\% CI -2.6 to -1.1 , p < $0.001)$ at 12 months and -2.1 ( $95 \% \mathrm{CI}-3.3$ to -1.0 , p < 0.01 ) at 24 months (Fig. 1B).

Overall, there were no significant changes in $\mathrm{mRS}$ scores compared with the mean (SD) baseline (3.2 [0.4]) at 12 months $(0.0,95 \% \mathrm{CI}-0.2$ to $0.2, \mathrm{p}<0.99)$ or 24 months $(0.1,95 \% \mathrm{CI}-0.2$ to $0.3, \mathrm{p}<0.99)$. However, during the study 2 patients each experienced a single-point improvement and single-point worsening in $\mathrm{mRS}$ score.

The mean (SD) F-M total and FMMS scores at baseline were 133.6 (20.9) and 30.4 (15.1), respectively. Both F-M total and FMMS scores improved significantly at each time point starting at month 1 . Compared with baseline, F-M total score improved significantly by 19.2 (95\% CI $11.4-27.0, \mathrm{p}<0.001)$ at 12 months and 19.4 (95\% CI 9.929.0, p < 0.01) at 24 months (Fig. 1C). FMMS score im-
TABLE 4 . TEAEs of $\geq 10 \%$ by decreasing frequency (study population)

\begin{tabular}{|c|c|c|c|c|}
\hline \multirow[b]{2}{*}{$\begin{array}{l}\text { System Organ Class } \\
\text { Preferred Term, n (\%) }\end{array}$} & \multicolumn{3}{|c|}{ Cell Dose } & \multirow[b]{2}{*}{ Pooled } \\
\hline & $\begin{array}{c}2.5 \times 10^{6} \\
(n=6)\end{array}$ & $\begin{array}{c}5.0 \times 10^{6} \\
(\mathrm{n}=6)\end{array}$ & $\begin{array}{c}10 \times 10^{6} \\
(n=6)\end{array}$ & \\
\hline Any TEAE & $6(100)$ & $6(100)$ & $6(100)$ & $18(100)$ \\
\hline $\begin{array}{l}\text { Headache/procedural } \\
\text { headache* }\end{array}$ & $6(100)$ & $4(66.7)$ & $6(100)$ & $16(88.9)$ \\
\hline Nausea & $0(0)$ & $3(50.0)$ & $3(50.0)$ & $6(33.3)$ \\
\hline Depression & $0(0)$ & $2(33.3)$ & $2(33.3)$ & $4(22.2)$ \\
\hline Muscle spasticity & $2(33.3)$ & $1(16.7)$ & $1(16.7)$ & $4(22.2)$ \\
\hline Vomiting & $0(0)$ & $2(33.3)$ & $2(33.3)$ & $4(22.2)$ \\
\hline Blood glucose increase & $2(33.3)$ & $1(16.7)$ & $0(0)$ & $3(16.7)$ \\
\hline $\begin{array}{l}\text { C-reactive protein } \\
\text { increase }\end{array}$ & $1(16.7)$ & $1(16.7)$ & $1(16.7)$ & $3(16.7)$ \\
\hline Constipation & $0(0)$ & $2(33.3)$ & $1(16.7)$ & $3(16.7)$ \\
\hline Fatigue & $0(0)$ & $1(16.7)$ & $2(33.3)$ & $3(16.7)$ \\
\hline Pain in extremity & $2(33.3)$ & $1(16.7)$ & $0(0)$ & $3(16.7)$ \\
\hline Urinary tract infection & $1(16.7)$ & $0(0)$ & $2(33.3)$ & $3(16.7)$ \\
\hline Arthralgia & $2(33.3)$ & $0(0)$ & $0(0)$ & $2(11.1)$ \\
\hline Convulsion & $1(16.7)$ & $1(16.7)$ & $0(0)$ & $2(11.1)$ \\
\hline Decreased appetite & $0(0)$ & $2(33.3)$ & $0(0)$ & $2(11.1)$ \\
\hline Diarrhea & $0(0)$ & $1(16.7)$ & $1(16.7)$ & $2(11.1)$ \\
\hline Dizziness & $1(16.7)$ & $1(16.7)$ & $0(0)$ & $2(11.1)$ \\
\hline Dysphagia & $0(0)$ & $1(16.7)$ & $1(16.7)$ & $2(11.1)$ \\
\hline Hypesthesia & $1(16.7)$ & $1(16.7)$ & $0(0)$ & $2(11.1)$ \\
\hline Muscle spasms & $0(0)$ & $1(16.7)$ & $1(16.7)$ & $2(11.1)$ \\
\hline Musculoskeletal pain & $1(16.7)$ & $1(16.7)$ & $0(0)$ & $2(11.1)$ \\
\hline Pneumocephalus & $0(0)$ & $2(33.3)$ & $0(0)$ & $2(11.1)$ \\
\hline Pneumonia & $0(0)$ & $0(0)$ & $2(33.3)$ & $2(11.1)$ \\
\hline Subdural hematoma & $0(0)$ & $2(33.3)$ & $0(0)$ & $2(11.1)$ \\
\hline
\end{tabular}

Values are presented as the number of patients (\%) unless stated otherwise.

* Headaches were coded into 2 terms due to reporting verbatim differences. 
TABLE 5. TEAES ( $\geq 3$ ) occurring by relationship to cell treatment or surgical procedure by decreasing frequency

\begin{tabular}{|c|c|c|c|c|c|c|c|c|c|c|}
\hline \multirow[b]{2}{*}{$\begin{array}{l}\text { System Organ Class } \\
\text { Preferred Term, n (\%) }\end{array}$} & \multirow{2}{*}{$\begin{array}{l}\text { Relationship } \\
\text { to Cell } \\
\text { Treatment* }^{*}\end{array}$} & \multicolumn{4}{|c|}{ Cell Dose } & \multirow{2}{*}{$\begin{array}{l}\text { Relationship } \\
\text { to Surgical } \\
\text { Procedure }^{*}\end{array}$} & \multicolumn{4}{|c|}{ Cell Dose } \\
\hline & & $\begin{array}{c}2.5 \times 10^{6} \\
(n=6)\end{array}$ & $\begin{array}{c}5.0 \times 10^{6} \\
(n=6)\end{array}$ & $\begin{array}{c}10 \times 10^{6} \\
(n=6)\end{array}$ & $\begin{array}{l}\text { Pooled } \\
(n=18)\end{array}$ & & $\begin{array}{c}2.5 \times 10^{6} \\
(n=6)\end{array}$ & $\begin{array}{c}5.0 \times 10^{6} \\
(n=6)\end{array}$ & $\begin{array}{c}10 \times 10^{6} \\
(n=6)\end{array}$ & $\begin{array}{l}\text { Pooled } \\
(n=18)\end{array}$ \\
\hline \multirow{5}{*}{ Any TEAE } & Unrelated & $6(100)$ & $6(100)$ & $5(83.3)$ & $17(94.4)$ & Unrelated & $6(100)$ & $6(100)$ & $5(83.3)$ & $17(94.4)$ \\
\hline & Unlikely & $5(83.3)$ & $2(33.3)$ & $3(50.0)$ & $10(55.6)$ & Unlikely & $4(66.7)$ & $1(16.7)$ & $1(16.7)$ & $6(33.3)$ \\
\hline & Possibly & $1(16.7)$ & $0(0)$ & $0(0)$ & $1(5.6)$ & Possibly & $1(16.7)$ & $5(83.3)$ & $3(50.0)$ & $9(50.0)$ \\
\hline & - & - & - & - & - & Probably & $3(50.0)$ & $3(50.0)$ & $4(66.7)$ & $10(55.6)$ \\
\hline & - & - & - & - & - & Definitely & $2(33.3)$ & $4(66.7)$ & $2(33.3)$ & $8(44.4)$ \\
\hline \multirow{4}{*}{$\begin{array}{l}\text { Headache/procedural } \\
\text { headache }\end{array}$} & Unrelated & $3(50.0)$ & $3(50.0)$ & $3(50.0)$ & $9(50.0)$ & Unrelated & $0(0)$ & $1(16.7)$ & $0(0)$ & $1(5.6)$ \\
\hline & Unlikely & $3(50.0)$ & $1(16.7)$ & $3(50.0)$ & $7(38.9)$ & Possibly & $1(16.7)$ & $2(33.3)$ & $1(16.7)$ & $4(22.2)$ \\
\hline & - & - & - & - & - & Probably & $3(50.0)$ & $1(16.7)$ & $3(50.0)$ & $7(38.9)$ \\
\hline & - & - & - & - & - & Definitely & $2(33.3)$ & $1(16.7)$ & $2(33.3)$ & $5(27.8)$ \\
\hline \multirow{3}{*}{ Muscle spasticity } & Unrelated & $1(16.7)$ & $0(0)$ & $1(16.7)$ & 2 (11.1) & Unrelated & $1(16.7)$ & $0(0)$ & $1(16.7)$ & $2(11.1)$ \\
\hline & Unlikely & $0(0)$ & $1(16.7)$ & $0(0)$ & $1(5.6)$ & Unlikely & $0(0)$ & $1(16.7)$ & $0(0)$ & $1(5.6)$ \\
\hline & Possibly & $1(16.7)$ & $0(0)$ & $0(0)$ & $1(5.6)$ & Possibly & $1(16.7)$ & $0(0)$ & $0(0)$ & $1(5.6)$ \\
\hline \multirow{2}{*}{ Nausea } & Unrelated & $0(0)$ & $2(33.3)$ & $2(33.3)$ & $4(22.2)$ & Unrelated & $0(0)$ & $1(16.7)$ & $1(16.7)$ & $2(11.1)$ \\
\hline & Unlikely & $0(0)$ & $1(16.7)$ & $1(16.7)$ & $2(11.1)$ & Possibly & $0(0)$ & $2(33.3)$ & $2(33.3)$ & $4(22.2)$ \\
\hline Depression & Unrelated & $0(0)$ & $2(33.3)$ & $2(33.3)$ & $4(22.2)$ & Unrelated & $0(0)$ & $2(33.3)$ & $2(33.3)$ & $4(22.2)$ \\
\hline \multirow{2}{*}{ Vomiting } & Unrelated & $0(0)$ & $2(33.3)$ & $2(33.3)$ & $4(22.2)$ & Unrelated & $0(0)$ & $1(16.7)$ & $1(16.7)$ & $2(11.1)$ \\
\hline & - & - & - & - & - & Possibly & $0(0)$ & $1(16.7)$ & $1(16.7)$ & $2(11.1)$ \\
\hline Blood glucose increased & Unrelated & $2(33.3)$ & $1(16.7)$ & $0(0)$ & $3(16.7)$ & Unrelated & $2(33.3)$ & $1(16.7)$ & $0(0)$ & $3(16.7)$ \\
\hline \multirow{2}{*}{ Constipation } & Unrelated & $0(0)$ & $1(16.7)$ & $1(16.7)$ & $2(11.1)$ & Unrelated & $0(0)$ & $2(33.3)$ & $0(0)$ & $2(11.1)$ \\
\hline & Unlikely & $0(0)$ & $1(16.7)$ & $0(0)$ & $1(5.6)$ & Possibly & $0(0)$ & $0(0)$ & $1(16.7)$ & $1(5.6)$ \\
\hline \multirow{2}{*}{$\begin{array}{l}\text { C-reactive protein } \\
\text { increased }\end{array}$} & Unrelated & $0(0)$ & $1(16.7)$ & $1(16.7)$ & $2(11.1)$ & Unrelated & $0(0)$ & $1(16.7)$ & $1(16.7)$ & $2(11.1)$ \\
\hline & Unlikely & $1(16.7)$ & $0(0)$ & $0(0)$ & $1(5.6)$ & Unlikely & $1(16.7)$ & $0(0)$ & $0(0)$ & $1(5.6)$ \\
\hline \multirow{2}{*}{ Fatigue } & Unrelated & $0(0)$ & $1(16.7)$ & $2(33.3)$ & $3(16.7)$ & Unrelated & $0(0)$ & $0(0)$ & $1(16.7)$ & $1(5.6)$ \\
\hline & - & - & - & - & - & Possibly & $0(0)$ & $1(16.7)$ & $1(16.7)$ & $2(11.1)$ \\
\hline \multirow{2}{*}{ Pain in extremity } & Unrelated & $2(33.3)$ & $1(16.7)$ & $0(0)$ & $3(16.7)$ & Unrelated & $2(33.3)$ & $0(0)$ & $0(0)$ & $2(11.1)$ \\
\hline & - & - & - & - & - & Probably & $0(0)$ & $1(16.7)$ & $0(0)$ & $1(5.6)$ \\
\hline Urinary tract infection & Unrelated & $1(16.7)$ & $0(0)$ & $2(33.3)$ & $3(16.7)$ & Unrelated & $1(16.7)$ & $0(0)$ & $2(33.3)$ & $3(16.7)$ \\
\hline
\end{tabular}

- = not applicable.

* The relationship to cell treatment/surgical procedure and adverse events (TEAEs) was evaluated by the investigator according to the guidance outlined in Table 3 .

proved significantly by 11.4 (95\% CI $4.6-18.2$, p < 0.001$)$ at 12 months and $10.4(95 \% \mathrm{CI} 4.0-16.7, \mathrm{p}<0.01)$ at 24 months (Fig. 1D), with maximal improvement in FMMS score achieved by 7 patients (38.9\%) at month 3 .
Improvement in ESS, NIHSS, and F-M scores plateaued by 12 months and had not declined at 24 months.

Thirteen patients (72.2\%) achieved clinically meaningful improvement (at least a 10-point increase in FMMS

TABLE 6. Serious adverse events

\begin{tabular}{|c|c|c|c|c|}
\hline \multirow[b]{2}{*}{ Verbatim Term/Preferred Term } & \multirow{2}{*}{$\begin{array}{c}\text { Cell } \\
\text { Dose }\end{array}$} & \multicolumn{2}{|c|}{ Relationship to: } & \multirow[b]{2}{*}{ Outcome } \\
\hline & & Cell Treatment & Surgical Procedure & \\
\hline Seizure & \multirow{2}{*}{$2.5 \times 10^{6}$} & Unrelated & Probably & Recovered/resolved \\
\hline Stenting of asymptomatic carotid artery stenosis & & Unrelated & Unrelated & Recovered/resolved \\
\hline Asymptomatic subdural hematoma/hygroma & \multirow{4}{*}{$5.0 \times 10^{6}$} & Unrelated & Definitely & Recovered/resolved \\
\hline Transient ischemic attack & & Unrelated & Unrelated & Recovered/resolved \\
\hline Hypesthesia & & Unlikely & Unrelated & Recovered/resolved \\
\hline Dysphagia & & Unlikely & Unrelated & Recovered/resolved \\
\hline Urinary tract infection & \multirow{3}{*}{$10 \times 10^{6}$} & Unrelated & Unrelated & Recovered/resolved \\
\hline Sepsis & & Unrelated & Unrelated & Recovered/resolved \\
\hline Pneumonia & & Unlikely & Possibly & Recovered/resolved \\
\hline
\end{tabular}



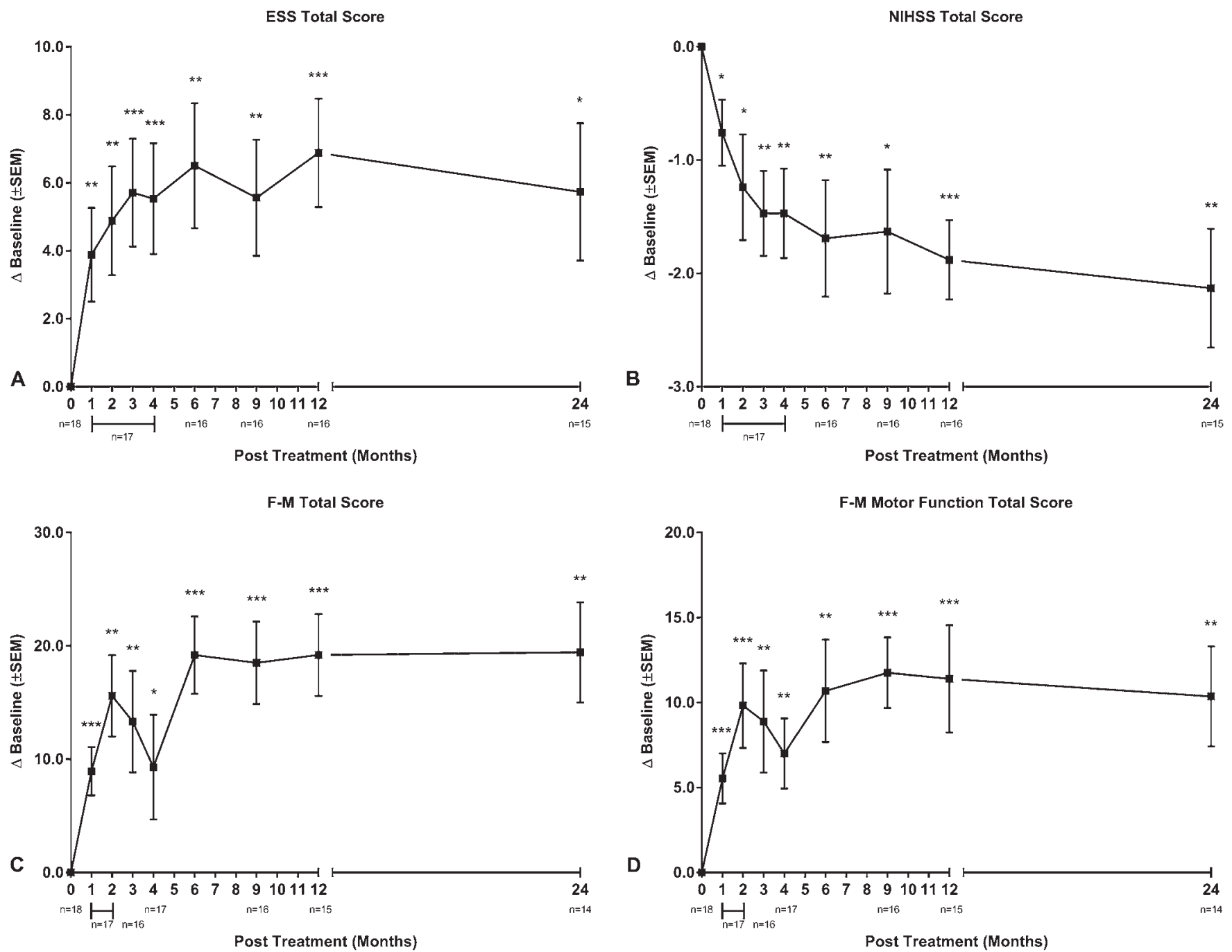

FIG. 1. Evaluation of clinical outcome endpoints at 24 months (intent-to-treat population, $n=18$ ). A: ESS total score. B: NIHSS total score. C: F-M total score. D: FMMS total score. ${ }^{*} p<0.05,{ }^{* *} p<0.01,{ }^{* * *} p<0.001$.

score from baseline) at a mean (SD) of 78.4 (64.1) days, with first achievement of clinically meaningful improvement occurring in 9 of 13 patients (69.2\%) by month 2 (Fig. $2 \mathrm{~A})$. For the 13 patients who achieved clinically meaningful improvement, the greatest significant mean change in FMMS score from baseline was +12.4 points at month 2 (Fig. 2B). This compared with the greatest significant mean change of FMMS score from baseline of +1.5 points at month 2 for 5 patients who did not achieve clinically meaningful improvement (Fig. 2B). For both groups, there were no significant differences in mean change of FMMS score from 2 months compared with subsequent time points. A comparison of patients who achieved and those who did not achieve clinically meaningful improvement showed that first achievement of at least $75 \%$ of maximal improvement occurred significantly sooner in patients who achieved clinically meaningful improvement (mean [SD]: 92.1 [65.2] days vs 184.4 [107.5] days, $\mathrm{p}<0.05$ ).

During the study, there were no correlations between improvement in clinical outcomes and cell dose, baseline patient age, or baseline stroke severity.
We previously reported significant correlations in a post hoc analysis between the size of newly appearing transient lesions on T2-weighted FLAIR, primarily in or adjacent to the premotor cortex at weeks 1-2 (which resolved by months 1-2), and improvement of 4 clinical outcomes scores (ESS total, NIHSS total, F-M total, and FMMS scores) in 13 of 18 patients at 12 months. ${ }^{33}$ At month 24, the size of transient lesions on T2-weighted FLAIR continued to be significantly correlated to improvements in ESS total score $(0.619, \mathrm{p}<0.05)$ and NIHSS total score $(-0.735, \mathrm{p}<0.01)$, but not F-M total score or FMMS score.

\section{Discussion}

\section{Safety and Clinical Outcomes}

In this completed phase $1 / 2$ a study, intracerebral stereotactic implantation of modified allogeneic SB623 cells in chronic stroke patients was generally safe and well tolerated at 2 years. Most TEAEs were of mild or moderate intensity. No TEAEs were assessed as probably or definitely related to cell treatment, but, as in a previous study, 
FMMS: Time to First Achievement of Clinically Meaningful Improvement (at least 10 Points)

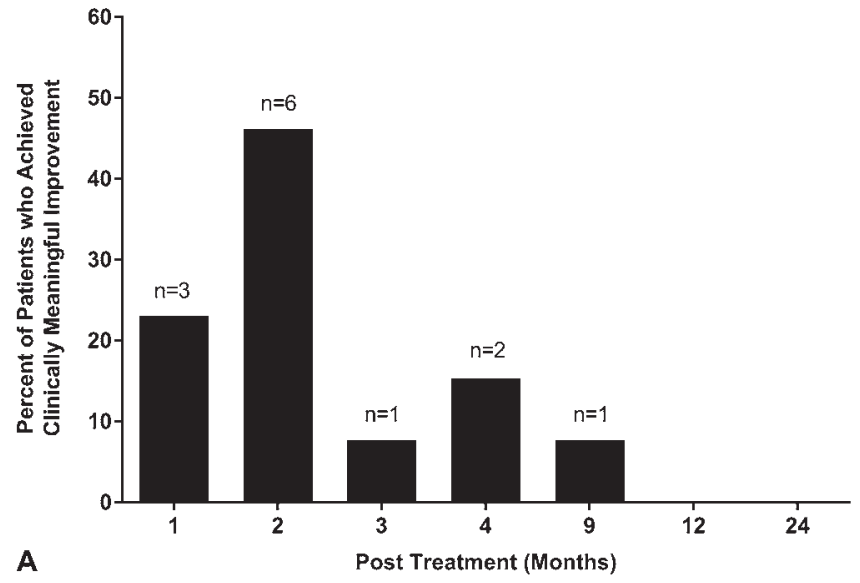

Number of TEAEs/SAEs at 0 to 1 Year and $>1$ to 2 Years

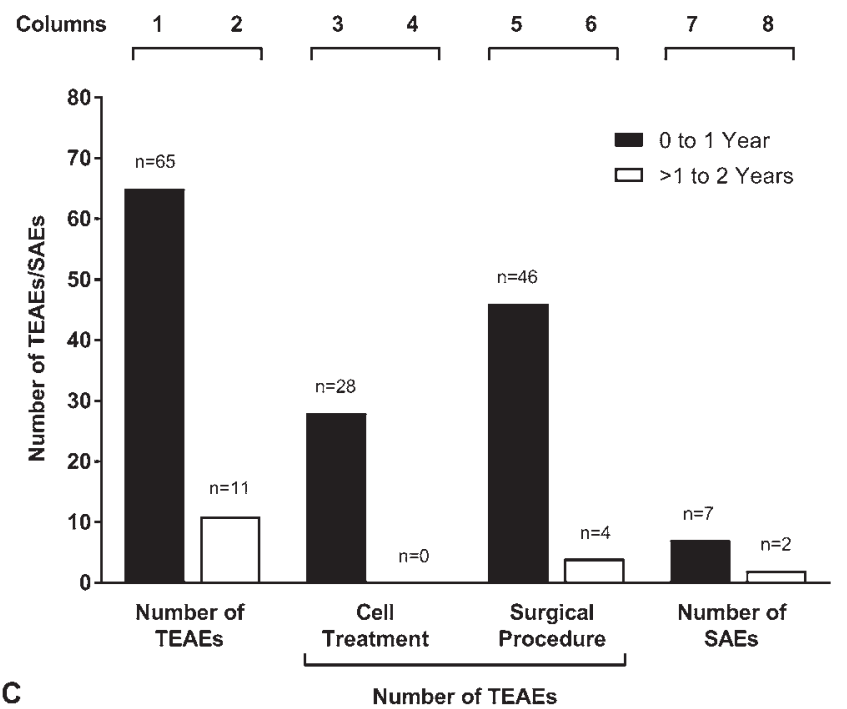

Mean FMMS Change from Baseline for Patients Who Achieved Versus Did Not Achieve Clinically Meaningful Improvement (at least 10 Points)

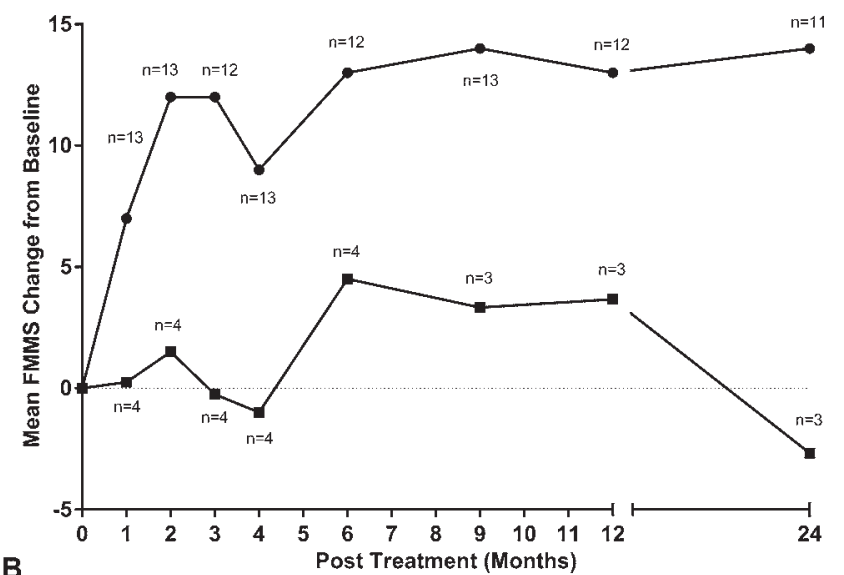

Mean FMMS for Patients who Achieved Clinically Meaningful Improvement

- Mean FMMS for Patients who did not Achieve Clinically Meaningful Improvement

FIG. 2. A: Time to first achievement of clinically meaningful improvement $(n=13)$. B: Mean F-M motor function total score change from baseline for patients who achieved $(n=13)$, and did not achieve clinically meaningful improvement $(n=5)$. C: Number of TEAEs (columns 1 and 2), number of TEAEs associated with cell treatment (columns 3 and 4), number of TEAEs associated with surgical procedure (columns 5 and 6 ), and number of SAEs (columns 7 and 8 ) at 0 to 1 year and $>1$ to 2 years.

numerous TEAEs were assessed as probably or definitely related to the surgical procedure. ${ }^{23}$ This is not unexpected in an invasive study that utilized craniostomy and direct introduction of cell product into the brain parenchyma. During the study, the vast majority of TEAEs and SAEs occurred during the 1st year after implantation of SB623 cells. Specifically, 65 TEAEs occurred during the 1st year with a frequency of $\geq 10 \%$, with an additional 11 TEAEs occurring during the 2 nd year of the study (Fig. 2C). These findings suggest that adverse events that occurred during the study were mostly associated with the surgical procedure, rather than long-term effects associated with the implantation of SB623 cells. However, the larger number of follow-up visits during the 1 st compared with the 2 nd year (9 vs 1) could also explain the increased number of TEAEs and SAEs reported during the 1st year after im- plantation. In addition, no adverse events were associated with the presence of antibodies to SB623 HLAs. Although 1 patient had preexisting antibodies to SB623 HLAs, no patient developed antibodies to SB623 HLAs during the study. These findings are important given the allogeneic background of SB623 cells and their potential for immunoreactivity.

During PISCES, an observational phase 1 clinical study, 11 chronic stroke patients who underwent implantation of allogeneic modified human neural stem cells experienced mostly mild TEAEs during a median follow-up of 44 months. Fifteen SAEs were reported during 23 months of follow-up, with 3 assessed as definitely related to the surgical procedure, and there was no evidence for the development of antibodies to HLAs. ${ }^{21}$ In a single-blind, controlled phase 2 clinical study of 15 chronic stroke patients who 
underwent implantation of autologous peripheral blood stem cells, no SAEs related to implantation were reported after 1 year. ${ }^{8}$ Although different stem cell types were implanted in patients in these small-scale, early-phase clinical studies, the studies utilized similar intracerebral stereotactic surgical procedures. Overall, investigators have deemed the implantation of stem cells as being safe, with no evidence of immunoreactivity, and with adverse events being mainly associated with the surgical procedure. , $^{8,21}$

Two years after implantation of SB623 cells, chronic stroke patients in this completed phase $1 / 2$ a study experienced significant improvement in motor impairment scales compared with baseline, specifically ESS, NIHSS, F-M total, and FMMS scores. Improvement in motor impairment scale scores after 2 years was sustained from interim 1-year data, and the primary clinical outcome measure of significant improvement in ESS score at 6 months compared with baseline was achieved. ${ }^{33}$ Although our phase $1 / 2$ a study lacked a control arm, the improvement in motor impairment scale scores was unlikely to be a placebo effect, as these patients had chronic, stable neurological deficits $\geq 6$ months following their stroke, at which point no therapy had been shown to improve function, and the improvement was maintained for 2 years. However, we cannot absolutely exclude a placebo effect, and this is currently being tested in an ongoing phase $2 \mathrm{~b}$ randomized, double-blind, placebo-controlled study (ACTIsSIMA). In addition, no correlation was found between cell dosage and improvement in clinical outcomes during the study. This may be due to the small sample size in this study; it could also be a reflection of preclinical data using animal models of stroke that have reported that lower doses of implanted mesenchymal stem cells are associated with greater improvement in motor function. ${ }^{41}$

Two years after implantation of modified human neural stem cells in the PISCES study, chronic stroke patients experienced improvements in NIHSS score, Ashworth leg and arm scores, and the Barthel Index activity score..$^{21}$ The mRS score was unchanged in 7 patients, improved in 3 patients, and worsened in a single patient. After 1 year in another phase 2 study investigating intracerebral implantation of autologous peripheral blood stem cells, chronic stroke patients experienced significant improvement in ESS, ESS motor subscale, NIHSS, and mRS scores compared with baseline and untreated controls. ${ }^{8}$ Our completed phase 1/2a study and other early-phase clinical studies have reported improvement in several measures of motor impairment, activity, and disability in chronic stroke patients.

Although some improvement in mRS score was reported in an early-phase clinical study, ${ }^{8}$ we did not see a significant mean change from baseline for $\mathrm{mRS}$ score in this phase $1 / 2$ a study at 2 years. The mRS is a disability scale used in the acute and subacute stroke setting, and its utility in chronic stroke has not been validated. ${ }^{3,38}$ Given the scope of the mRS, it is predictable that we were not able to measure a significant mean change from baseline during the 2 years after treatment. Improvements in motor function after stroke have been reported to plateau at 6 months irrespective of stroke severity, with the greatest improvement occurring during the month following the stroke event. ${ }^{11,12,19}$ Patients were enrolled in this study at least 6 months after stroke onset and were therefore in the chronic stroke setting at baseline.

The FMMS score is recognized as a valid and reliable motor impairment scale for the assessment of recovery from chronic stroke. ${ }^{13,16,34}$ At least a 10-point (10\%) increase from baseline in FMMS score is accepted as a clinically meaningful improvement in chronic stroke. ${ }^{14,26,39,40} \mathrm{In}$ this study, the mean FMMS score increased from baseline by 10.4 points at 2 years, showing that, on average, patients experienced a clinically meaningful improvement. Moreover, 13 patients achieved clinically meaningful improvement during the study in a mean of 78.4 days, with first achievement occurring in 9 patients by month 2 . In addition, first achievement of at least $75 \%$ of maximum improvement in FMMS score occurred significantly sooner (92.3 days) in patients who achieved clinically meaningful improvement than in those who did not. Overall, these findings show that not only did the majority of patients who underwent implantation with SB623 cells experience clinically meaningful improvement at 2 years, but most did so by 2 months after implantation. These findings suggest that SB623 cells may have their greatest effect on patients during the initial months following implantation, with these effects sustained at 2 years.

\section{T2-Weighted FLAIR Imaging}

We previously reported in a post hoc analysis significant correlations between the size of transient lesions in the ipsilateral cortex detected by T2-weighted FLAIR imaging with improvements in clinical outcomes scores at 1 year. ${ }^{33}$ Significant correlations continued between the size of transient lesions and improvement in the ESS and NIHSS total scores at 2 years. As implanted SB623 cells only survive for a short period (usually less than 1 month) in xenograft models, ${ }^{35,44}$ the sustained neurological recovery seen in this study may result from paracrine effects secondary to implanted cell secreted proteins and molecules that mediate reduction in inflammation, changes in cell signaling, and enhanced endogenous plasticity, rather than the integration and long-term survival of SB623 cells in the peri-infarction area. ${ }^{43}$ How long the human cells would remain viable in a human host after implantation is not known but is not expected to be more than 1 month. The causes of these transient lesions on T2weighted FLAIR imaging are unclear but may indicate the presence of inflammation, graft-host reaction, or possibly gliosis. Given the small number of patients in the study, it is difficult to ascertain the importance of these transient lesions and their relationship or necessity for stroke recovery. Their association with the improvement of clinical outcomes, however, is most compelling and warrants further investigation.

\section{Study Limitations}

The findings of this study are encouraging but should be interpreted with caution given the small scale and uncontrolled study design. In addition, this study utilized a highly selective patient screening process, such that only $4.7 \%$ of screened patients were enrolled in the study. Furthermore, this study used NIHSS evaluations as a baseline 
definition for stable chronic stroke. Although this definition has been used previously, other studies have alternatively defined stable chronic stroke at baseline using other stroke scales.

\section{Conclusions}

This report presents 2-year data from our completed phase $1 / 2$ a study to evaluate the safety and clinical outcomes of intracerebral stereotactic implantation of SB623 cells in patients with stable chronic ischemic stroke. Consistent with the 1-year interim data, treatment with SB623 cells at 2 years was safe and well tolerated, and was associated with significant improvements in clinical outcomes in patients with stable chronic stroke. The favorable findings of this study highlight the potential of SB623 cells as a treatment for patients with chronic ischemic stroke; as such, a randomized, double-blind, controlled phase $2 \mathrm{~b}$ (ACTIsSIMA) study is currently active. In this study, approximately 156 chronic stroke patients from 65 sites in the United States will be implanted stereotactically with either $2.5 \times 10^{6}$ or $5.0 \times 10^{6} \mathrm{SB} 623$ cells or will undergo sham (partial burr hole) placebo surgery in a 1:1:1 ratio stratified by mRS score at screening. The study will run for 1 year, with the primary efficacy endpoint being the proportion of patients who achieve an improvement in FMMS score of at least 10 points at 6 months compared with baseline.

\section{Acknowledgments}

The authors thank Anthony Stonehouse, $\mathrm{PhD}$, of Watson \& Stonehouse Enterprises, LLC, who provided medical writing support for this project, which was funded by SanBio, Inc. We also thank Cindy H. Samos and Christine Plant for assistance with the manuscript.

\section{References}

1. Aizman I, Tate CC, McGrogan M, Case CC: Extracellular matrix produced by bone marrow stromal cells and by their derivative, SB623 cells, supports neural cell growth. J Neurosci Res 87:3198-3206, 2009

2. Azad TD, Veeravagu A, Steinberg GK: Neurorestoration after stroke. Neurosurg Focus 40(5):E2, 2016

3. Balu S: Differences in psychometric properties, cut-off scores, and outcomes between the Barthel Index and Modified Rankin Scale in pharmacotherapy-based stroke trials: systematic literature review. Curr Med Res Opin 25:13291341, 2009

4. Benjamin EJ, Blaha MJ, Chiuve SE, Cushman M, Das SR, Deo R, et al: Heart disease and stroke statistics-2017 update: a report from the American Heart Association. Circulation 135:e146-e603, 2017 (Errata in Circulation 135:e646, 2017; Circulation 136:e196, 2017)

5. Bonita R, Beaglehole R: Recovery of motor function after stroke. Stroke 19:1497-1500, 1988

6. Brott T, Adams HP Jr, Olinger CP, Marler JR, Barsan WG, Biller J, et al: Measurements of acute cerebral infarction: a clinical examination scale. Stroke 20:864-870, 1989

7. Centers for Disease Control and Prevention: Stroke signs and symptoms. CDC.gov. (https://www.cdc.gov/stroke/signs_ symptoms.htm) [Accessed July 10, 2018]

8. Chen DC, Lin SZ, Fan JR, Lin CH, Lee W, Lin CC, et al: Intracerebral implantation of autologous peripheral blood stem cells in stroke patients: a randomized phase II study. Cell Transplant 23:1599-1612, 2014
9. Clarke DJ, Forster A: Improving post-stroke recovery: the role of the multidisciplinary health care team. J Multidiscip Healthc 8:433-442, 2015

10. Douketis JD, Spyropoulos AC, Spencer FA, Mayr M, Jaffer AK, Eckman MH, et al: Perioperative management of antithrombotic therapy. Antithrombotic therapy and prevention of thrombosis, 9th ed: American College of Chest Physicians evidence-based clinical practice guidelines. Chest 141 (2 Suppl):e326S-e350S, 2012

11. Duncan PW, Goldstein LB, Horner RD, Landsman PB, Samsa GP, Matchar DB: Similar motor recovery of upper and lower extremities after stroke. Stroke 25:1181-1188, 1994

12. Duncan PW, Goldstein LB, Matchar D, Divine GW, Feussner $\mathrm{J}$ : Measurement of motor recovery after stroke. Outcome assessment and sample size requirements. Stroke 23:10841089, 1992

13. Duncan PW, Propst M, Nelson SG: Reliability of the FuglMeyer assessment of sensorimotor recovery following cerebrovascular accident. Phys Ther 63:1606-1610, 1983

14. Feys HM, De Weerdt WJ, Selz BE, Cox Steck GA, Spichiger $\mathrm{R}$, Vereeck LE, et al: Effect of a therapeutic intervention for the hemiplegic upper limb in the acute phase after stroke: a single-blind, randomized, controlled multicenter trial. Stroke 29:785-792, 1998

15. Fugl-Meyer AR, Jääskö L, Leyman I, Olsson S, Steglind S: The post-stroke hemiplegic patient. 1. A method for evaluation of physical performance. Scand J Rehabil Med 7:13-31, 1975

16. Gladstone DJ, Danells CJ, Black SE: The Fugl-Meyer assessment of motor recovery after stroke: a critical review of its measurement properties. Neurorehabil Neural Repair 16:232-240, 2002

17. Goldstein LB, Bertels C, Davis JN: Interrater reliability of the NIH stroke scale. Arch Neurol 46:660-662, 1989

18. Hantson L, De Weerdt W, De Keyser J, Diener HC, Franke C, Palm R, et al: The European Stroke Scale. Stroke 25:22152219, 1994

19. Hendricks HT, van Limbeek J, Geurts AC, Zwarts MJ: Motor recovery after stroke: a systematic review of the literature. Arch Phys Med Rehabil 83:1629-1637, 2002

20. Jeong H, Yim HW, Cho YS, Kim YI, Jeong SN, Kim HB, et $\mathrm{al}$ : Efficacy and safety of stem cell therapies for patients with stroke: a systematic review and single arm meta-analysis. Int J Stem Cells 7:63-69, 2014

21. Kalladka D, Sinden J, Pollock K, Haig C, McLean J, Smith $\mathrm{W}$, et al: Human neural stem cells in patients with chronic ischaemic stroke (PISCES): a phase 1, first-in-man study. Lancet 388:787-796, 2016

22. Kondziolka D, Steinberg GK, Cullen SB, McGrogan M: Evaluation of surgical techniques for neuronal cell transplantation used in patients with stroke. Cell Transplant 13:749754,2004

23. Kondziolka D, Steinberg GK, Wechsler L, Meltzer CC, Elder E, Gebel J, et al: Neurotransplantation for patients with subcortical motor stroke: a phase 2 randomized trial. J Neurosurg 103:38-45, 2005

24. Lemmens R, Steinberg GK: Stem cell therapy for acute cerebral injury: what do we know and what will the future bring? Curr Opin Neurol 26:617-625, 2013

25. Lo AC, Guarino P, Krebs HI, Volpe BT, Bever CT, Duncan PW, et al: Multicenter randomized trial of robot-assisted rehabilitation for chronic stroke: methods and entry characteristics for VA ROBOTICS. Neurorehabil Neural Repair 23:775-783, 2009

26. Page SJ, Levine P, Khoury JC: Modified constraint-induced therapy combined with mental practice: thinking through better motor outcomes. Stroke 40:551-554, 2009

27. Powers WJ, Derdeyn CP, Biller J, Coffey CS, Hoh BL, Jauch EC, et al: American Heart Association Stroke Council. 2015 
American Heart Association/American Stroke Association Focused update of the 2013 guidelines for the early management of patients with acute ischemic stroke regarding endovascular treatment: a guideline for healthcare professionals from the American Heart Association/American Stroke Association. Stroke 46:3020-3035, 2015

28. Rabinovich SS, Seledtsov VI, Banul NV, Poveshchenko OV, Senyukov VV, Astrakov SV, et al: Cell therapy of brain stroke. Bull Exp Biol Med 139:126-128, 2005

29. Rai AT, Seldon AE, Boo S, Link PS, Domico JR, Tarabishy AR, et al: A population-based incidence of acute large vesse occlusions and thrombectomy eligible patients indicates significant potential for growth of endovascular stroke therapy in the USA. J Neurointerv Surg 9:722-726, 2017

30. Rankin J: Cerebral vascular accidents in patients over the age of 60. II. Prognosis. Scott Med J 2:200-215, 1957

31. Richards CL, Malouin F, Nadeau S: Stroke rehabilitation: clinical picture, assessment, and therapeutic challenge. Prog Brain Res 218:253-280, 2015

32. Sanford J, Moreland J, Swanson LR, Stratford PW, Gowland C: Reliability of the Fugl-Meyer assessment for testing motor performance in patients following stroke. Phys Ther 73:447454, 1993

33. Steinberg GK, Kondziolka D, Wechsler LR, Lunsford LD, Coburn ML, Billigen JB, et al: Clinical outcomes of transplanted modified bone marrow-derived mesenchymal stem cells in stroke: a phase 1/2a study. Stroke 47:1817-1824, 2016

34. Sullivan KJ, Tilson JK, Cen SY, Rose DK, Hershberg J, Correa A, et al: Fugl-Meyer assessment of sensorimotor function after stroke: standardized training procedure for clinical practice and clinical trials. Stroke 42:427-432, 2011

35. Tajiri N, Kaneko Y, Shinozuka K, Ishikawa H, Yankee E, McGrogan M, et al: Stem cell recruitment of newly formed host cells via a successful seduction? Filling the gap between neurogenic niche and injured brain site. PLoS One 8:e74857, 2013

36. Teasell R, Foley N, Hussein N, Salter K, Cotoi A, Richardson $\mathrm{M}$ : Evidence-based review of stroke rehabilitation (17th edition). EBSR.org. (http://www.ebrsr.com/sites/default/files/ documents/executive-summary-srebr_final_16ed.pdf) [Accessed July 10, 2018]

37. Unsworth DJ, Mathias JL, Dorstyn DS: Cell therapies administered in the chronic phase after stroke: a meta-analysis examining safety and efficacy. Regen Med 12:91-108, 2017

38. Uyttenboogaart M, Stewart RE, Vroomen PC, De Keyser J, Luijckx GJ: Optimizing cutoff scores for the Barthel index and the modified Rankin scale for defining outcome in acute stroke trials. Stroke 36:1984-1987, 2005

39. van der Lee JH, Beckerman H, Lankhorst GJ, Bouter LM: The responsiveness of the Action Research Arm test and the Fugl-Meyer Assessment scale in chronic stroke patients. J Rehabil Med 33:110-113, 2001

40. van der Lee JH, Wagenaar RC, Lankhorst GJ, Vogelaar TW, Devillé WL, Bouter LM: Forced use of the upper extremity in chronic stroke patients: results from a single-blind randomized clinical trial. Stroke 30:2369-2375, 1999

41. Vu Q, Xie K, Eckert M, Zhao W, Cramer SC: Meta-analysis of preclinical studies of mesenchymal stromal cells for ischemic stroke. Neurology 82:1277-1286, 2014

42. Wade D: Rehabilitation - a new approach. Part three: the implications of the theories. Clin Rehabil 30:3-10, 2016

43. Wechsler LR, Bates D, Stroemer P, Andrews-Zwilling YS,
Aizman I: Cell therapy for chronic stroke. Stroke 49:10661074, 2018

44. Yasuhara T, Matsukawa N, Hara K, Maki M, Ali MM, Yu SJ, et al: Notch-induced rat and human bone marrow stromal cell grafts reduce ischemic cell loss and ameliorate behavioral deficits in chronic stroke animals. Stem Cells Dev 18:15011514,2009

\section{Disclosures}

This study was partly conducted at Stanford University School of Medicine and Stanford Health Care (SHC) and was funded by a contract with SanBio, Inc., which provided principal investigator, co-investigator, and coordinator fees. Dr. Steinberg and Dr. Schwartz are Stanford University School of Medicine employees. Dr. Steinberg is a consultant for Qool Therapeutics, Peter Lazic US, Inc., and NeuroSave.

This study was partly conducted at the University of Pittsburgh Medical School and University of Pittsburgh Medical Center (UPMC), and was funded by a contract with SanBio, Inc., which provided principal investigator and coordinator fees. Dr. Wechsler and Dr. Lunsford are employees of the University of Pittsburgh Medical School and UPMC. Dr. Kondziolka is a former employee of UPMC, and was a consultant for Elekta AB. Dr. Wechsler is a stockholder in Silk Road Medical and Remedy Pharm, is a consultant for Athersys and SanBio, Inc., and receives unrelated grant funding from Athersys, Inc. Dr. Lunsford is a consultant for and stockholder of Elekta AB and serves on the DSMB for Insightec. Personnel support for a principal investigator in this study was provided by the University of California, San Francisco, and was funded by a contract with SanBio, Inc. Dr. Kim is an employee of the University of California, San Francisco, and receives unrelated grant funding from BioGen Idec. Dr. Bates and Dr. McGrogan are full-time employees of SanBio, Inc. Dr. Poggio received consultancy fees from SanBio, Inc. and owns Biostatistical Consulting Inc., which provides statistical services to SanBio Inc. Dr. Case and Dr. Yankee are former employees and current stockholders of SanBio, Inc. Dr. Yankee is a consultant for SanBio, Inc. Dr. McGrogan is a stockholder of SanBio, Inc.

\section{Author Contributions}

Conception and design: Steinberg, Kondziolka, Wechsler, Case, Yankee, Schwartz. Acquisition of data: Steinberg, Kondziolka, Wechsler, Lunsford, Kim, Johnson, Bates, McGrogan, Schwartz. Analysis and interpretation of data: Steinberg, Kondziolka, Lunsford, Bates, Yankee, Schwartz. Critically revising the article: Steinberg. Reviewed submitted version of manuscript: Steinberg. Approved the final version of the manuscript on behalf of all authors: Steinberg. Statistical analysis: Poggio.

\section{Supplemental Information}

Previous Presentations

Portions of this work were presented in abstract form and as an oral presentation at the International Stroke Conference 2018, Los Angeles, California, January 24-26, 2018.

\section{Correspondence}

Gary Steinberg: Stanford University School of Medicine and Stanford Healthcare, Stanford, CA. cerebral@stanford.edu. 